\title{
Gamma Interferon Induces Monocytoid Differentiation in the HL-60 Cell Line
}

\author{
Edward D. Ball, Paul M. Guyre, Li Shen, John M. Glynn, \\ Charles R. Maliszewski, Paul E. Baker, \\ and Michael $\mathbf{W}$. Fanger \\ Departments of Microbiology, Medicine, and Physiology, \\ Dartmouth Medical School, Hanover, New Hampshire 03756; \\ Department of Veterinary Research, Montana State University, \\ Bozeman, Montana 59715
}

A recombinant DNA-derived interferons (IFN) to induce phenotypic changes in cells of the HL-60 promyelocytic leukemia cell line. Changes in cell surface markers detected by monoclonal antibodies as well as morphologic, histochemical, and functional changes were monitored. We found that gamma $(\gamma)$ IFN, but not alpha $(\alpha)$ or beta $(\beta) I F N$, induced the expression of antigens characteristic of monocytes and granulocytes (AML-2-23, 63D3, and 61D3), as well as changes in morphology consistent with monocytoid differentiation. These included induction of $\alpha$-naphthyl acetate esterase, increased cell size, and a decrease in azurophilic granules. The $\gamma$-IFN dose dependency and time course of the effect on antigen expression suggest that de novo protein synthesis was induced by $\gamma$ IFN. The activity of $\gamma$-IFN and of mixed-lymphocyte culture supernatant was blocked by a monoclonal antibody to $\gamma$-IFN. Significant augmentation in the ability of the HL-60 cells to mediate antibody-dependent cellular cytotoxicity was induced by $\gamma$-IFN. These findings suggest that $\gamma$-IFN plays a role in the regulation of hematopoiesis.

\section{Introduction}

A number of studies have documented the ability of the HL60 promyelocytic leukemia cell line to differentiate along either a granulocytic or monocytic pathway, depending upon the inducing agent used (1-4). Polar planar substances such as dimethyl

Received for publication 22 September 1983 and in revised form 8 December 1983.

J. Clin. Invest.

(c) The American Society for Clinical Investigation, Inc.

0021-9738/84/04/1072/06 \$1.00

Volume 73, April 1984, 1072-1077 sulfoxide (DMSO) ${ }^{1}$ or dimethylformamide and retinoic acid can induce striking granulocytic differentiation $(1,2)$, while phorbol diesters and supernatants from stimulated lymphocytes have been shown to cause these cells to undergo monocytoid differentiation $(3,4)$. Changes concomitant with morphologic differentiation also occur in the expression of cell surface antigens, some of which have been defined using monoclonal antibodies (MoAbs) (5-9).

We have previously shown (9) that an antigen shared by monocytes and granulocytes, defined by MoAb AML-2-23, can be induced on cells of the HL-60 line by incubation with either granulopoietic inducers such as DMSO or by lymphocyte supernatants, but not by phorbol diester treatment. Induction of differentiation with mixed-lymphocyte culture supernatants (MLC-SUP) involved primarily the increased expression of cytoplasmic $\alpha$-naphthyl acetate esterase (nonspecific esterase) and a decreased nuclear/cytoplasmic ratio. In contrast, treatment of the cells with phorbol diester induced more profound monocytoid differentiation resulting in many of the cells attaching to plastic surfaces and extending pseudopods. The factors present in MLC-SUP that induce neoantigen expression as well as histochemical and morphologic changes have previously been unknown. In this report, we present evidence that immune or gamma interferon ( $\gamma$-IFN) is capable of mimicking the activity of MLC-SUP and we propose that this lymphokine is involved in the induction of differentiation in the HL-60 line.

\section{Methods}

Cells. The HL-60 promyelocytic leukemia cell line (10) was provided by Dr. Robert Gallo, of the National Institutes of Health, Bethesda, MD. Cells were continuously cultured in a serum-free defined medium (modified Iscove's medium [11]). For comparison, a variety of other

1. Abbreviations used in this paper: $\mathrm{ADCC}$, antibody-dependent cellular cytotoxicity; $\mathrm{CE}$, chicken erythrocyte; CSF-1, colony-stimulating factor1; DMSO, dimethyl sulfoxide; FBS, fetal bovine serum; IFN, interferon; MLC-SUP, mixed-lymphocyte culture supernatants; MoAb, monoclonal antibody. 
culture media were used, including RPMI-1640 (K. C. Biologicals, St. Louis, MO) supplemented with $10 \%$ fetal bovine serum (FBS) (Sterile Systems Inc., Logan, UT), Immunex modified Iscove's medium (Immunex, Inc., Seattle, WA), and Iscove's medium, supplied by $\mathbf{K}$. C. Biologicals. All media were supplemented with $50 \mu \mathrm{g} / \mathrm{ml}$ of gentamicin (Schering Corp., Kenilworth, NJ).

Monoclonal antibodies. MoAb AML-2-23, an IgG2b antibody that reacts strongly with monocytes and less so with granulocytes (8) was used in this study to monitor phenotypic changes. In addition, the reactivity of MoAbs PM-81(12), PMN 29(8), PMN 6(8), OKIal (Ortho Diagnostic Systems, Inc., Westwood, MA), 61D3(13), and 63D3(13) with control and treated cells was determined. Control MoAbs included AML-1-201 (8), which reacts with $\beta-2$ microglobulin, the IgGl antibody produced by the P3 hybridoma parent cell line, and an IgG2b MoAb of irrelevant specificity. All studies were conducted with saturating amounts of purified MoAbs $(20 \mu \mathrm{g} / \mathrm{ml})$.

To quantify the number of AML-2-23 binding sites, the Fab portion of MoAb AML-2-23 was prepared by papain cleavage (14), affinity chromatography on protein A-Sepharose 4B, and gel filtration on Sephadex $\mathrm{G} 100$, and was iodinated by the chloramine $\mathrm{T}$ method (15). Control and treated cells were incubated for $2 \mathrm{~h}$ at $4^{\circ} \mathrm{C}$ with a saturating dose of ${ }^{125} \mathrm{I}$-Fab in the presence or absence of excess unlabeled MoAb AML-2-23. Free and bound antibody were separated by centrifugation on an oil cushion (16) and the radioactivity in supernatants and cell pellets was determined. After correcting for nonspecific binding, the number of AML-2-23 receptor sites per cell was estimated from the specific activity of the radiolabeled Fab.

Induction of phenotypic change with IFN. $\alpha-, \beta-$, and $\gamma$-IFN produced in Escherichia coli from recombinant human DNA (17-19) were generously provided by Dr. Costa Sevastopoulos (Genentech Inc., San Francisco, CA) for these studies. The purity of these preparations was $>95 \%$ as established by sodium dodecyl sulfate-polyacrylamide gel electrophoresis and silver staining (20). The levels of endotoxin in IFN preparations and media were measured in a Limulus amebocyte assay (21). Cells from the HL-60 line were seeded at 125,000 cells/ml in six-well plastic tissue culture plates to which were added varying concentrations of each of the IFN species. To establish a dose-response relationship, cells were cultured with increasing concentrations of interferons $(0.1-$ $10^{4}$ anti-viral $\mathrm{U} / \mathrm{ml}, \alpha$-IFN as standard) for $3 \mathrm{~d}$ at $37^{\circ} \mathrm{C}$ in a $5 \% \mathrm{CO}_{2}$ humidified atmosphere and removed for morphologic evaluation and for binding to MoAbs. The morphology of treated and control cells was evaluated by Wright's-Giemsa stain on cytofuge preparations. Staining for $\alpha$-naphthyl acetate esterase was also performed (22). MoAb binding was evaluated by cytofluorography. A study of the time dependency for $\gamma$-IFN induction was performed during which $500 \mathrm{U}$ of $\gamma$-IFN was added serially on each of $7 \mathrm{~d}$ to cells previously seeded as above.

Blocking of $\gamma$-IFN activity by a MoAb to $\gamma$-IFN. To verify that the activity being measured in both the $\gamma$-IFN preparations and MLC supernatants was $\gamma$-IFN, we attempted to block activity with a MoAb to $\gamma$-IFN. An IgGl MoAb that neutralizes $\gamma$-IFN activity was generously provided for these studies by Drs. Junming Le and Jan T. Vilcek of New York University Medical Center. $100 \mathrm{U}$ of $\gamma$-IFN (in $20 \mu$ ) or MLC-SUP $(20 \mu l)$ was incubated with $20 \mu$ l of supernatant (either diluted $1: 10$ with medium or undiluted) from the anti- $\gamma$-IFN hybridoma, $\mathrm{B}-3$, or the $\mathrm{P3}$ myeloma cell line at $37^{\circ} \mathrm{C}$ for $1 \mathrm{~h}$. This mixture was added to freshly seeded HL-60 cells. To control for the possibility that immune complexes could nonspecifically block $\gamma$-IFN activity, we added a mixture of human nerve growth factor and an IgG MoAb specific for nerve growth factor to some cultures. In addition, to further ensure specificity, the B-3 MoAb was added to cultures in the presence of $1 \%$
DMSO. $5 \mathrm{~d}$ later, AML-2-23 antigen induction on these and control cells was determined by cytofluorography. In addition, the ability of these cells to mediate antibody-dependent cellular cytotoxicity (ADCC) was measured (see below).

Effect of colony-stimulating factor (CSF-1) and endotoxin on $\mathrm{HL}$ 60 cells. HL-60 cells were cultured in serum-free medium with increasing concentrations of purified CSF-1 (1-500 units/ml) (kindly provided by Dr. Richard Stanley, Albert Einstein Medical College, Bronx, NY) or endotoxin $\left(0.01-10^{3} \mathrm{ng} / \mathrm{ml}\right.$ ) (Associates of Cape Cod, Inc., Woods Hole, MA). After $5 \mathrm{~d}$ the cells were analyzed for morphologic change and for changes in cell-surface antigen expression.

Cytofluorographic analysis. Control and treated cells were incubated with purified MoAbs at $20 \mu \mathrm{g} / \mathrm{ml}$ for 30 min at $4^{\circ} \mathrm{C}$. After washing with phosphate-buffered saline (pH 7.4), containing $0.05 \%$ sodium azide and $0.1 \%$ bovine serum albumin, fluorescein isothiocyanate conjugated-goat $\mathrm{F}\left(\mathrm{ab}^{\prime}\right)_{2}$ antibody directed to mouse antibody (Boehringer Mannheim Biochemicals, Indianapolis, IN) was added and incubation continued for $30 \mathrm{~min}$ at $4^{\circ} \mathrm{C}$. After washing, the cells were analyzed by flow cytometry on the Ortho Cytofluorograph System $50 \mathrm{H}$ with the Ortho computer system 2150 (Ortho Diagnostic Systems, Inc.).

$A D C C$. ADCC was performed as previously described (23). Briefly, chicken erythrocytes (CE) freshly drawn into heparin were washed once and $10 \mu \mathrm{l}$ of pelleted cells were labeled with $100 \mu \mathrm{Ci}\left[{ }^{51} \mathrm{Cr}\right]$ sodium chromate (New England Nuclear, Boston, MA). Effector HL-60 cells, cultured as indicated, were mixed in round-bottomed microtiter wells with an equal volume of labeled CE $\left(1 \times 10^{5} / \mathrm{ml}\right)$ and a $10^{-5}$ dilution of a rabbit anti-CE IgG fraction (stock solution $16 \mathrm{mg} / \mathrm{ml}$ ). After $6 \mathrm{~h}$ incubation at $37^{\circ} \mathrm{C}$, half the supernate was removed and assessed for ${ }^{51} \mathrm{Cr}$ content. Results are expressed as mean \pm SD of triplicate wells. Percentage specific cytotoxicity was calculated as follows: $100 \times[$ (release by effectors + antibody) - (release by effectors without antibody)]/ [maximum lysis - spontaneous release].

\section{Results}

Induction of morphologic change. Approximately $50 \%$ of cells cultured in the presence of $\gamma$-IFN exhibited a lower nuclear/ cytoplasmic ratio and the loss of azurophilic granules. The cells remained in suspension and did not attach to the plastic culture wells. Sorting of these cells by fluorescence on the cytofluorograph and observation of their morphology on cytofuge preparations revealed that AML-2-23-positive cells were a homogeneous population of large cells with abundant agranular cytoplasm. Staining of treated cells for nonspecific esterase revealed that $\sim 60 \%$ of cells were induced by $\gamma$-IFN to display strong cytoplasmic staining while control cells were all negative. $\alpha$ and $\beta$-IFN did not induce such morphologic or histochemical changes. Proliferation of HL-60 cells was decreased by only $20 \%$ during exposure to $\alpha$ - and $\beta$-IFN for $6 \mathrm{~d}$ while $\gamma$-IFN had no effect, as determined by $\left[{ }^{3} \mathrm{H}\right]$ thymidine incorporation. Cells treated with IFN and control cells were $>95 \%$ viable as determined by staining with acridine orange and ethidium bromide.

Measurement of monoclonal antibody binding to cells. The percentage of untreated HL-60 cells bearing the AML-2-23 antigen varied with the medium used. Less than $10 \%$ of the cells cultured in serum-free modified Iscove's medium expressed the AML-2-23 antigen even when endotoxin at concentrations 
ranging from 0.01 to $10^{3} \mathrm{ng} / \mathrm{ml}$ or CSF-1 $(1-500 \mathrm{U} / \mathrm{ml})$ was added (data not shown). The activity of CSF-1 was verified by its ability to support growth of colonies derived from peripheral blood mononuclear cells of normal donors in methylcellulose cultures (24). Cells cultured in RPMI containing $10 \%$ FBS, or in Immunex medium, expressed the AML-2-23 antigen on 15$40 \%$ of cells probably in response to differentiating agents such as retinoids which are found in serum.

The experiment shown in Fig. 1 indicates that $\sim 50 \%$ of HL-60 cells were induced by $\gamma$-IFN to express the AML-2-23 antigen. In six experiments, the range of AML-2-23 positive cells following $\gamma$-IFN treatment was $50-75 \%$. The effect of $\gamma$ IFN was near maximal by day 5 in experiments in which cells were cultured in medium to which $500 \mathrm{U} / \mathrm{ml} \gamma$-IFN was initially added (Fig. 2). To control for the possibility that the AML-223 antibody may interact with induced HL-60 cells through Fcreceptors (25), competing human IgG at $300 \mu \mathrm{g} / \mathrm{ml}$ was mixed with AML-2-23 before incubation with treated cells. The degree of binding of AML-2-23 was unaffected by Fc-receptor blockade. Radioligand binding data (not shown) using ${ }^{125} \mathrm{I}-\mathrm{Fab}$ of the AML2-23 MoAb indicated that the average number of antigenic determinants increased from $\sim 6,000 /$ cell to 90,000 /cell during culture in the presence of $500 \mathrm{U} / \mathrm{ml} \gamma$-IFN. Cells cultured in the presence of $\alpha$ - and $\beta$-IFN revealed no change in the level of AML-2-23 antigen ( $<10 \%$ positive). The degree of induction of the AML-2-23 antigen by MLC-SUP was similar to that of $\gamma$-IFN at $500 \mathrm{U} / \mathrm{ml}$.

No significant difference in the binding of MoAbs PM-81, PMN 29, or PMN 6 was noted between control and IFN-treated cells (Table I). The binding of MoAbs 63D3 and 61D3 increased in parallel with AML-2-23, as previously reported (9). OKIa1 did not bind to HL-60 cells before or after IFN exposure. Of interest is that the expression of $\beta-2$-microglobulin was found to be quite low on control cells cultured in serum-free medium and that $\gamma$-IFN was capable of inducing this antigen.

Effect of anti- $\gamma-I F N M O A b$ on activity of $\gamma-I F N$ and of $M L C$ $S U P$. As seen in Table II, compared with a control MoAb of the same IgG subclass, the MoAb to $\gamma$-IFN, B-3, effectively neutralized the activity of both purified $\gamma$-IFN and of MLCSUP. No effect of either nonspecific immune complexes on $\gamma$ IFN-mediated antigen induction (Table II) or the B-3 MoAb on DMSO-mediated AML-2-23 induction (data not shown) was noted. Moreover, the MoAb also inhibited the ability of $\gamma$-IFN and MLC-SUP to increase ADCC activity (Figs. 3-5).

$A D C C$. Unstimulated HL-60 cells possessed low levels of cytotoxicity to antibody-coated $\mathrm{CE}$, with $\sim 10 \%$ specific cytotoxicity at a ratio of $10 \mathrm{HL}-60$ cells to $1 \mathrm{CE}$ (Fig. 3). Cells cultured for $5 \mathrm{~d}$ under identical conditions in the presence of $\gamma$-IFN showed a three to fourfold increase in killing. This demonstrates that recombinant human $\gamma$-IFN is a potent inducer of ADCC by HL- 60 cells, in line with a previous report that IgG Fc receptor expression by this cell line is greatly elevated by recombinant $\gamma$-IFN (26). Cells cultured with $10 \mathrm{U} / \mathrm{ml} \gamma$ IFN in the presence of the MoAb specific for $\gamma$-IFN, B-3, did not show such strongly elevated cytotoxicity (Fig. 3). Although these cells still killed more effectively than untreated controls, the level of cytotoxicity was only half of that achieved by cells treated with $10 \mathrm{U} / \mathrm{ml} \gamma$-IFN.

Since the degree of cytotoxicity of $\gamma$-IFN treated cells was nearly identical over a range of effector to target ratios from 10

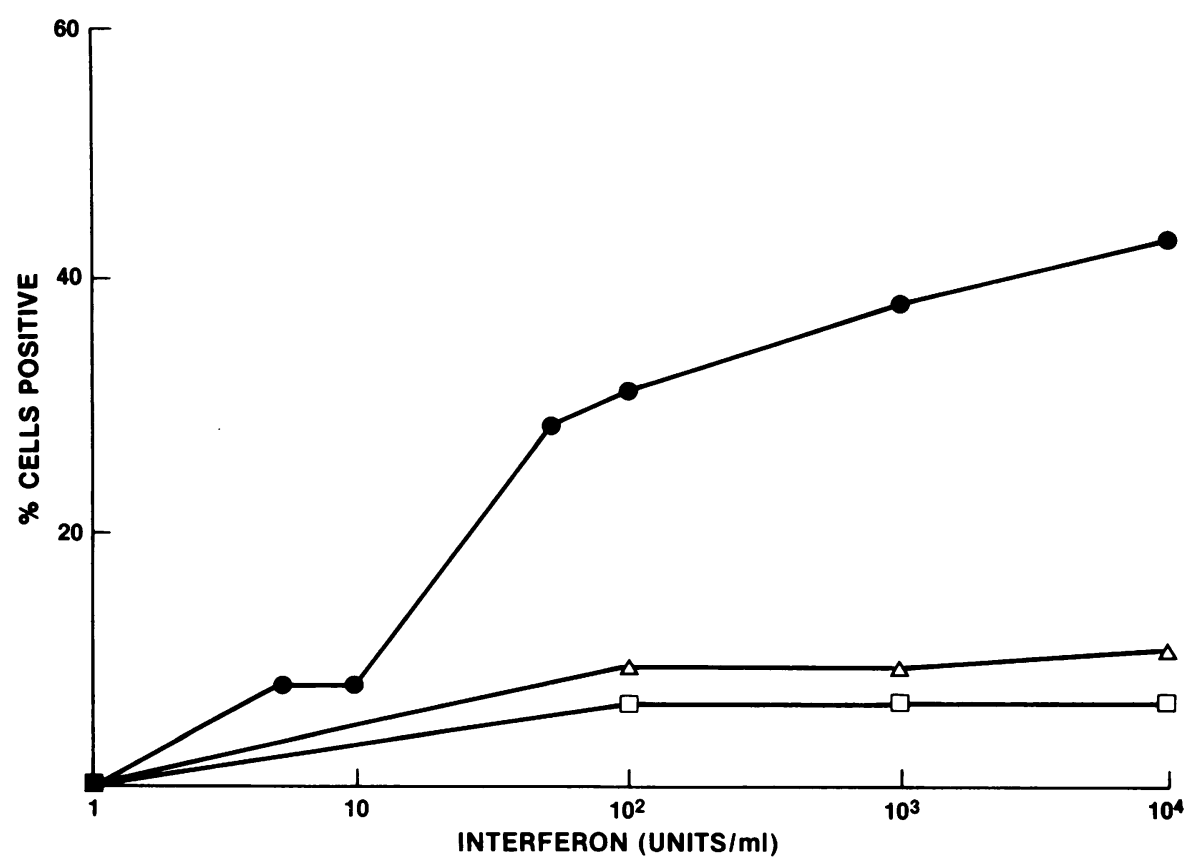

Figure 1. Induction of the AML-2-23 antigen on HL-60 cells cultured for $5 \mathrm{~d}$ in serum-free medium in the presence of each of the three species of IFN. The percentage of AML-2-23 positive cells, as determined by cytofluorography, increased from 0 to $45 \%$ during exposure to $\gamma$-IFN $(\bullet)$ in a dose-dependent manner, but only to $8 \%$ during exposure to $\alpha-(\Delta)$ or $\beta-(\square)$ IFN. The background staining of control MoAb was subtracted from the number of AML-2-23-positive cells. 


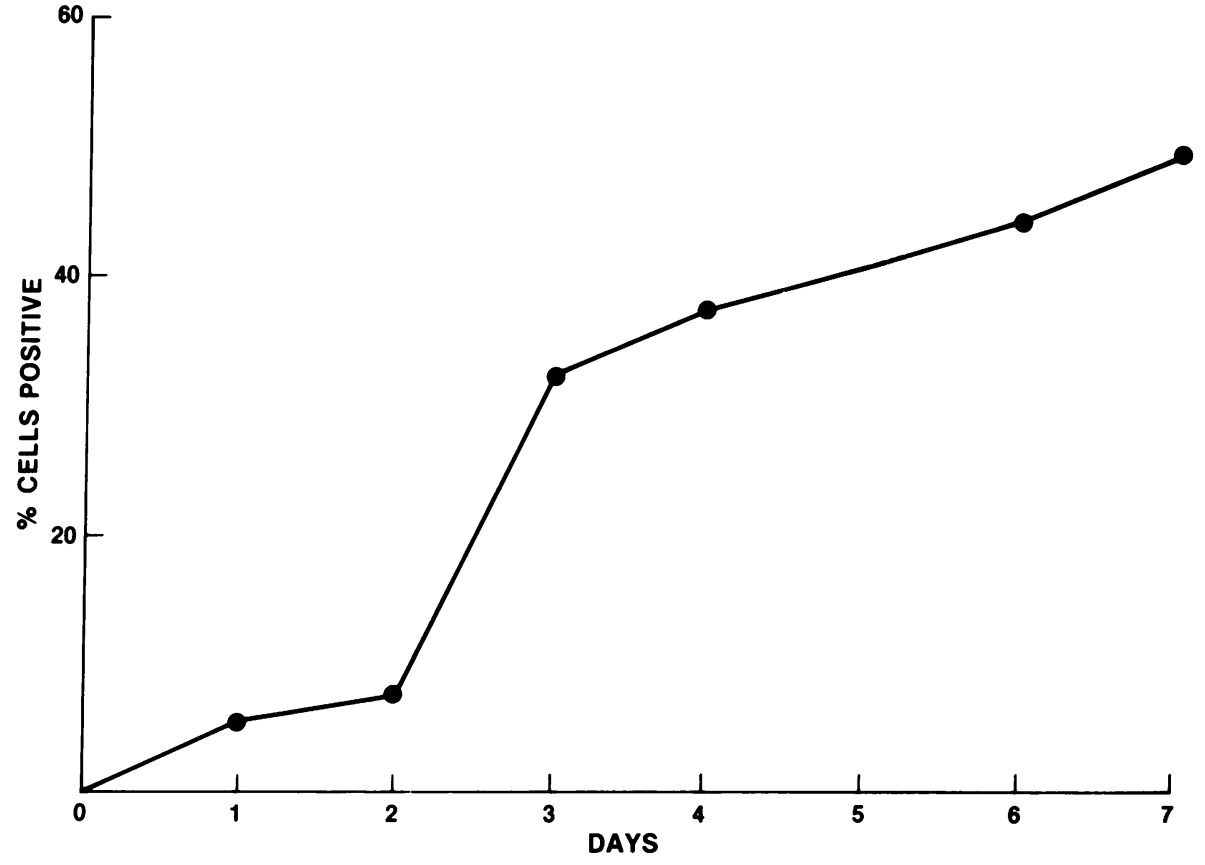

Figure 2. The percentage of AML-2-23 positive cells was dependent on time of exposure to $\gamma$-IFN $(500 \mathrm{U} / \mathrm{ml})$. The mean fluorescence intensity of $\gamma$-IFN treated cells increased from 6 on day 0 to 25 on day 7. The background staining of control MoAb was subtracted from the number of AML-2-23-positive cells. to 1.2 , other experiments were performed in which lower effector to target ratios were achieved. As shown in Fig. 4 the degree of killing was dependent on the ratio of effector to target cells at low effector to target ratios. Also of interest is the observation that treatment of HL-60 cells with DMSO did not induce in-

Table I. Effect of $\gamma$-IFN on Antigen Expression on $H L-60$ Cells Detected with MoAbs

\begin{tabular}{lcc}
\hline & \multicolumn{2}{c}{$\begin{array}{c}\text { Binding to HL-60 cells before and } \\
\text { after IFN treatment* }\end{array}$} \\
\cline { 2 - 3 } MoAbs & Control & Treated \\
\hline & $\%(M F I)$ & $\%(M F I)$ \\
AML-2-23 & $2(10)$ & $51(40)$ \\
PM-81 & $93(33)$ & $91(37)$ \\
PMN 29 & $80(31)$ & $83(35)$ \\
63D3 & $0(0)$ & $57(20)$ \\
61D3 & $0(0)$ & $59(20)$ \\
OKIa1 & $0(0)$ & $0(0)$ \\
AML-1-201 & $2(1)$ & $80(50)$
\end{tabular}

Numbers reported are the percentages of cells stained by MoAb less the percentages of control MoAb-positive cells (usually 1-2\%). The mean fluorescense intensity (MFI) of MoAb-stained cells was calculated from the equation: mean $=1 / n\left(n_{x} x\right)$, where $n$ is the total number of cells, $n_{x}$ is the number or cells in channel $x$, and $x$ is the channel number. Results are expressed as mean fluorescence of the experimental sample minus the mean fluorescence of the control.

* Cells were cultured in the presence of $500 \mathrm{U} / \mathrm{ml}$ of $\gamma$-IFN for $5 \mathrm{~d}$.
Table II. Neutralization by a MoAb to $\gamma-I F N$ of $\gamma$-IFN and MLC-SUP-mediated Induction of AML-2-23 Antigen*

\begin{tabular}{clcc}
\hline Exp & MoAb & $\gamma$-IFN* & MLC-SUP \\
\hline \multirow{3}{*}{1} & & $\%$ of control & \\
& B-3 & 12 & 32 \\
& CON & 100 & 100 \\
2 & B-3 & 2 & 0 \\
& CON & 100 & 100 \\
& IC & 100 & ND
\end{tabular}

* In experiment $1, \gamma$-IFN (200 U in $40 \mu \mathrm{l})$ or MLC-SUP (40 $\mu \mathrm{l})$ were incubated with an equal volume of supernatant from the hybridoma producing anti-IFN MoAb, B-3, or control supernatant (CON) (from the $\mathrm{P} 3$ myeloma line) for $1 \mathrm{~h}$ at $37^{\circ} \mathrm{C}$. This mixture was added in duplicate to HL-60 cells freshly seeded $\left(3 \times 10^{5}\right.$ cells $\left./ \mathrm{ml}\right)$ into 24-well cluster plates. In experiment 2 , a mixture of an irrelevant immune complex (IC) (nerve growth factor-anti-nerve growth factor) was added to some cultures to control for the possibility that immune complexes accounted for the inhibition of $\gamma$-IFN by B-3. CON in this experiment was supernatant from 7SN-60-4, a murine hybridoma producing an anti-nerve growth factor IgG MoAb. In both experiments, parallel cultures of HL-60 cells in the presence of $\gamma$-IFN $(100 \mathrm{U} / \mathrm{ml})$ or MLC-SUP ( $2 \%$ in experiment $1,10 \%$ in experiment 2$)$ were also conducted. After culture for $5 \mathrm{~d}$, these cells were analyzed by cytofluorography for the expression of the AML-2-23 antigen. The fluorescence of cells induced by $\gamma$-IFN or MLC-SUP in the presence of control MoAb was taken as $100 \%$. The relative fluorescence of cells induced in the presence of specific MoAb to $\gamma$-IFN, B-3, is shown. 


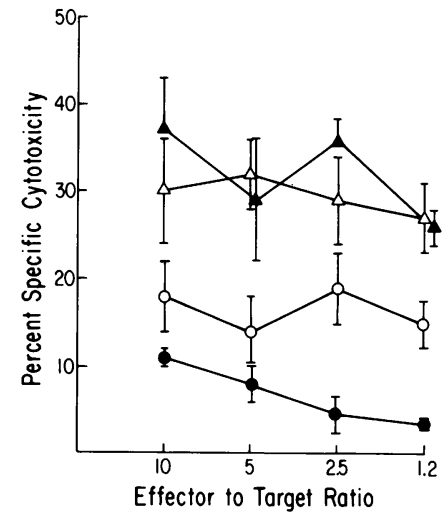

Figure 3. Enhancement of antibody-dependent cellular cytotoxicity by $\gamma$-IFN. The ability of HL-60 cells cultured for $5 \mathrm{~d}$ in the presence of $\gamma$-IFN at 10 $\mathrm{U} / \mathrm{ml}(\Delta)$ and $100 \mathrm{U} / \mathrm{ml}(\Delta)$ and control HL-60 cells $(\bullet)$ to kill ${ }^{51} \mathrm{Cr}$-labeled $\mathrm{CE}$ over a range of effector to target cell ratios is shown. Neutralization of $\gamma$-IFN by a MoAb specific for $\gamma$-IFN, B-3, resulted in $\sim 50 \%$ inhibition of the augmented ADCC activity (o).

creased ADCC activity despite the fact that granulocytic differentiation and neoantigen expression (AML-2-23) was induced on these cells.

Another experiment (Fig. 5) demonstrates blocking of MLCSUP-mediated induction of ADCC by the B-3 MoAb, further supporting the notion that $\gamma$-IFN is the active factor in MLC-SUP.

\section{Discussion}

These studies indicate that $\gamma$-IFN induces phenotypic changes consistent with monocytoid differentiation in cells of the HL60 promyelocytic leukemia cell line. We have previously shown that MLC-SUP are capable of inducing an identical change in the phenotype of HL-60 cells and the present report now demonstrates that this effect is duplicated by gene-cloned and essentially pure $\gamma$-IFN. Neither purified CSF-1 nor endotoxin were capable of inducing these effects. Since the $\gamma$-IFN concentration dependence of this effect is consistent with the levels of $\gamma$-IFN normally present in MLC-SUP, it would appear that the component in MLC-SUP primarily responsible for induction of monocytoid differentiation is $\gamma$-IFN. This interpretation is supported by the finding that the activity of both the cloned $\gamma$ IFN and MLC-SUP was blocked by a specific MoAb to $\gamma$-IFN. However, some contribution of other factors cannot be definitively excluded. Moreover, we have shown that the changes induced by $\gamma$-IFN are specific to this species of IFN and not

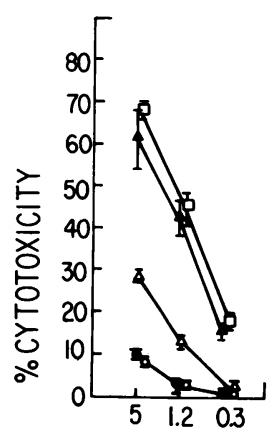

Figure 4. The enhancement of HL-60 ADCC by $\gamma$-IFN but not by DMSO, and the effect of monoclonal antibody to $\gamma$-IFN. HL-60 cells were cultured for $5 \mathrm{~d}$ in serum-free Iscove's medium alone $(\bullet)$, or supplemented with $250 \mathrm{U} / \mathrm{ml} \gamma$-IFN ( $\Delta$ ), $\gamma$-IFN plus MoAb specific for $\gamma$-IFN $(\Delta), \gamma$-IFN plus an irrelevant MoAb specific for nerve growth factor (), or 1\% DMSO (0). Cells were then compared for ability to mediate ADCC against rabbit IgG-coated chicken erythrocytes in $6 \mathrm{~h}$.

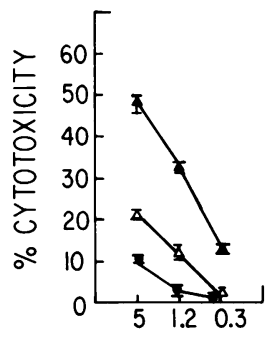

Figure 5. The enhancement of HL-60 ADCC by MLC supernatant and the effect of a MoAb against $\gamma$-IFN. HL-60 cells were cultured for $5 \mathrm{~d}$ in serum-free Iscove's medium alone (๑), or supplemented with MLC supernatant $(10 \%)(\triangle)$ or MLC supernatant with the addition of a MoAb specific for $\gamma$-IFN $(\Delta)$, and then compared for ability to kill rabbit IgG-coated chicken erythrocytes in $6 \mathrm{~h}$.

induced by either $\alpha$ - or $\beta$-IFN. 'The lack of effects with $\alpha$ - and $\beta$-IFNs are consistent with a recent report (27) also showing that no morphologic, antigenic, or functional changes were induced in the U937 line by these species of IFN.

In addition, these results demonstrate that the antigenic and morphologic changes induced by $\gamma$-IFN are accompanied by an increase in ADCC mediated by these cells. Since the ability to kill antibody-coated targets is a recognized property of mature cells of the myeloid series, this increase in cytotoxic capability appears to be related to overall differentiation of HL-60 cells. Other data, however, suggest that this interpretation may be an over-simplification. In particular, cloned $\gamma$-IFN has been shown to elevate Fc receptors (26) on HL-60 and U937 cells (26) and ADCC of U937 cells within $18 \mathrm{~h} \mathrm{(28)}$ although differentiation of HL-60 as assessed by appearance of the AML-2-23 antigen did not occur until $48 \mathrm{~h}$. It is possible, therefore, that $\gamma$-IFN enhancement of myeloid Fc receptor expression and ADCC may not be directly linked to differentiation. Further evidence in support of this notion is the failure of DMSO to induce ADCC despite the fact that this agent induces granulocytic differentiation of HL-60 cells (9).

The results of our study and of others $(29,30)$ indicate that IFN has important effects on hematopoiesis. Our findings also suggest the possibility that human $\gamma$-IFN may play a regulatory role in the process of monocyte/macrophage commitment from the myeloid progenitor pool as well as functional activation of these cells. It is interesting that not all HL-60 cells were inducible by $\gamma$-IFN, in contrast to the effects of chemical inducers such as DMSO or phorbol diester. We are presently studying the inducibility of individual clones of HL-60, in order to identify noninducible clones, and, therefore, identify differences between noninducible and inducible cells.

That $\gamma$-IFN induces monocytoid changes in the phenotype of HL-60 cells may have clinical significance. If cells from patients with acute myelogenous leukemia respond to $\gamma$-IFN in a similar manner, this agent could have therapeutic use as a differentiation agent, possibly in combination with other known differentiating agents such as the retinoids or 1,25-dihydrozyvitamin $D_{3}$. In addition to the possibility of terminally differentiating the leukemic clone, the induction of neoantigen expression could enhance MoAb-mediated cytolysis. Further studies that address these possibilities with both the HL-60 cell line and leukemia cells from patients with AML are in progress. 


\section{Acknowledgments}

This work was supported by grants CA 31888 , CA 31918 , CA17323, and AI 19053 awarded by the National Cancer Institute, Institute of Allergy and Infectious Diseases, and Department of Health and Human Services, respectively, and grant IN157 from the American Cancer Society. The cytofluorograph was the generous gift of the Fannie Rippel Foundation, and is partially supported by the core grant of the Norris Cotton Cancer Center (CA 23108).

\section{References}

1. Breitman, T. R., S. E. Selonick, and S. J. Collins. 1980. Induction of differentiation of the human promyelocytic leukemic cell line (HL60) by retinoic acid. Proc. Natl. Acad. Sci. USA. 77:2936-2940.

2. Collins, S. J., F. W. Ruscetti, R. E. Gallagher, and R. C. Gallo. 1978. Terminal differentiation of human promyelocytic leukemia cells induced by dimethyl sulfoxide and other polar compounds. Proc. Natl. Acad. Sci. USA. 75:2458-2462.

3. Rovera, G., T. G. O'Brien, and L. Diamond. 1979. Induction of differentiation in human promyelocytic leukemia cells by tumor promotors. Science (Wash. DC). 204:868-870.

4. Elias, L., F. J. Wogenrich, J. M. Wallace, and J. Longmire. 1980. Altered pattern of differentiation and proliferation of HL-60 promyelocytic leukemia cells in the presence of leukocyte conditioned medium. Leuk. Res. 4:301-307.

5. Gahmberg, C. G., K. Nilsson, and L. C. Anderson. 1979. Specific changes in the surface glycoprotein pattern of human promyelocytic leukemia cell line HL-60 during morphologic and functional differentiation. Proc. Natl. Acad. Sci. USA. 76:4087-4091.

6. Perussia, B., G. Trinchieri, D. Lebman, J. Jankiewicz, B. Lange, and G. Rovera. 1982. Monoclonal antibodies that detect differentiation surface antigens on human myelomonocytic cells. Blood. 59:382-392.

7. Griffin, J. D., J. Ritz, L. M. Nadler, and S. F. Schlossman. 1981 Expression of myeloid differentiation antigens on normal and malignant myeloid cells. J. Clin. Invest. 68:932-941.

8. Ball, E. D., R. F. Graziano, L. Shen, and M. W. Fanger. 1982. Monoclonal antibodies to novel myeloid antigens reveal human neutrophil heterogeneity. Proc. Natl. Acad. Sci. USA. 79:5374-5378.

9. Graziano, R. F., E. D. Ball, and M. W. Fanger. 1983. The expression and modulation of human myeloid-specific antigens during differentiation of the HL-60 cell line. Blood. 56:1215-1221.

10. Collins, S. J., R. C. Gallo, and R. E. Gallagher. 1977. Continuous growth and differentiation of human myeloid leukemic cells in suspension culture. Nature (Lond.). 270:347-349.

11. Iscove, N. N., L. J. Guilbert, and C. Weyman. 1980. Complete replacement of serum in primary cultures of erythropoietin-dependent red cell precursors (CFU-E) by albumin, transferrin, iron, unsaturated fatty acid, lecithin and cholesterol. Exp. Cell. Res. 126:121-126.

12. Ball, E. D., R. F. Graziano, and M. W. Fanger. 1983. A unique antigen expressed on myeloid cells and acute leukemia blast cells defined by a monoclonal antibody. J. Immunol. 130:2937-2941.

13. Ugolini, V., G. Nunez, R. G. Smith, P. Stasny, and J. D. Capra. 1981. Initial characterization of monoclonal antibodies against human monocytes. Proc. Natl. Acad. Sci. USA. 77:6764-6768.
14. Van Eyk, K. G. 1966. Fragmentation of human globulin with papain. Biochim. Biophys. Acta. 127:241-243.

15. Hunter, R. 1970. Standardization of the chloramine T method of protein iodination. Proc. Soc. Exp. Biol. Med. 133:989-992.

16. Crabtree, G. R. 1980. Fc receptors of a human promyelocytic leukemia cell line: evidence for two types of receptors defined by binding of the Staphylococcal protein A-IgG1 complex. J. Immunol. 125:448453.

17. Goeddel, D. V., D. W. Leung, T. J. Dull, M. Gross, R. M. Lawn, R. McCandliss, P. H. Seeburg, A. Ullrich, E. Yelverton, and P. W. Gray. 1981. The structure of eight distinct cloned human leukocyte interferon cDNAs. Nature (Lond.). 290:20-25.

18. Derynck, R., J. Content, E. DeClercq, G. Volckaert, J. Tavernier, R. Devos, and W. Fiers. 1980. Isolation and structure of a human fibroblast interferon gene. Nature (Lond.). 285:542-547.

19. Gray, P. W., D. W. Leung, D. Pennica, E. Yelverton, R. Najarian, C. C. Simonson, R. Derynck, P. Sherwood, D. M. Wallace, S. L. Berger, A. D. Levinson, and D. V. Goeddel. 1982. Expression of human immune interferon cDNA in E. coli and monkey cells. Nature (Lond.). 295:503508.

20. Oakley, B. R., D. R. Kirsch, and N. R. Morris. 1980. A simplified ultrasensitive silver stain for detecting proteins in polyacrylamide gels. Anal. Biochem. 105:361-363.

21. Sullivan, J. D., F. W. Valois, and S. W. Watson. 1976. Endotoxins: the limulus amebocyte lysate system. In Mechanisms in Bacterial Toxicology. A. W. Bernheimer, editor. John Wiley \& Sons, New York. 217.

22. Yam, L. T., C. Y. Li, and W. H. Crosby. 1971. Cytochemical identification of monocytes and granulocytes. Am. J. Clin. Pathol. 55:283-290.

23. Greenberg, A. H., L. Shen, and G. Medley. 1975. Characteristics of the effector cells mediating cytotoxicity against antibody-coated target cells. I. Phagocytic and non-phagocytic effector cell activity against erythrocyte and tumour target cells in a ${ }^{51} \mathrm{Cr}$ release cytotoxicity assay and ${ }^{125}$ I)IUDR growth inhibition assay. Immunology. 29:719-729.

24. Ball, E. D., and M. W. Fanger. 1983. The expression of myeloid specific antigens on myeloid leukemia cells: correlations with leukemia subclass and implications for normal myeloid differentiation. Blood. 56:456-463.

25. Guyre, P. M., G. R. Crabtree, J. E. Bodwell, and A. Munck. 1981. MLC-conditioned media stimulate an increase in Fc receptors on human macrophages. J. Immunol. 126:666-668.

26. Guyre, P. M., P. M. Morganelli, and R. Miller. 1983. Recombinant immune interferon increases immunoglobulin $\mathrm{G} F \mathrm{c}$ receptors on cultured human mononuclear phagocytes. J. Clin. Invest. 72:393-397.

27. Hattori, T., M. Pack, P. Bougnoux, Z.-L. Chang, and T. Hoffman. 1983. Interferon-induced differentiation of U937 cells. J. Clin. Invest. 72:237-244.

28. Shen, L., P. M. Guyre, and M. W. Fanger. 1984. Direct stimulation of ADCC by recombinant interferon: studies using a human monocytelike cell line (U937). Mol. Immunol. In press.

29. Klimpel, G. R., W. R. Fleischmann, and K. D. Klimpel. 1982. Gamma interferon (IFN $\gamma$ ) and IFN $\alpha / \beta$ suppress murine myeloid colony formation (CFU-C). Magnitude of suppression is dependent upon level of colony-stimulating factor (CSF). J. Immunol. 129:76-80.

30. Lee, S. H., and L. B. Epstein. 1980. Reversible inhibition by interferon of the maturation of human periphereal blood monocytes to macrophages. Cell. Immunol. 50:177-190. 